\title{
Evaluation on Impact Interaction between Abutment and Steel Girder Subjected to Nonuniform Seismic Excitation
}

\author{
Yue Zheng, ${ }^{1}$ Xiang Xiao, ${ }^{2}$ Lunhai Zhi, ${ }^{3}$ and Guobo Wang ${ }^{3}$ \\ ${ }^{1}$ Department of Civil and Environmental Engineering, Hong Kong Polytechnic University, Kowloon, Hong Kong \\ ${ }^{2}$ School of Transportation, Wuhan University of Technology, Wuhan 430070, China \\ ${ }^{3}$ School of Civil Engineering and Architecture, Wuhan University of Technology, Wuhan 430070, China \\ Correspondence should be addressed to Xiang Xiao; cexiaox@163.com
}

Received 1 September 2014; Accepted 27 September 2014

Academic Editor: Bo Chen

Copyright (C) 2015 Yue Zheng et al. This is an open access article distributed under the Creative Commons Attribution License, which permits unrestricted use, distribution, and reproduction in any medium, provided the original work is properly cited.

\begin{abstract}
This paper aims to evaluate the impact interaction between the abutment and the girder subjected to nonuniform seismic excitation. An impact model based on tests is presented by taking material properties of the backfill of the abutment into consideration. The conditional simulation is performed to investigate the spatial variation of earthquake ground motions. A two-span continuous steel box girder bridge is taken as the example to analyze and assess the pounding interaction between the abutment and the girder. The detailed nonlinear finite element (FE) model is established and the steel girder and the reinforced concrete piers are modeled by nonlinear fiber elements. The pounding element of the abutment is simulated by using a trilinear compression gap element. The elastic-perfectly plastic element is used to model the nonlinear rubber bearings. The comparisons of the pounding forces, the shear forces of the nonlinear bearings, the moments of reinforced concrete piers, and the axial pounding stresses of the steel girder are studied. The made observations indicate that the nonuniform excitation for multisupport bridge is imperative in the analysis and evaluation of the pounding effects of the bridges.
\end{abstract}

\section{Introduction}

Long span bridges are subjected to environmental loadings and dynamic excitations due to the interaction between the bridges and the surrounding environment [1-3]. External excitations acting on bridges, such as earthquakes, may induce the structural deformation and stresses due to the indeterminacy, which may cause the damage events of the structural components $[4,5]$. The out-of-phase oscillation in adjacent structures due to the difference in dynamic characteristics and the spatial variations of earthquake ground motion may result in the collision if their structural separation is not enough to accommodate the relative displacement. Reconnaissance shows that the pounding scenario is one of the most critical factors resulting in damages and failures of highway bridges [6]. The collision between bridge decks and abutments commonly results in the extensive damages to the highway bridges with seat abutment in many earthquakes, such as the 1971 San Fernando earthquake. Desroches and Fenves [7] reported that the frame stiffness ratios, earthquake loading, hinge gap, frame yield strength, and restrainer stiffness are the major factors in quantizing the pounding effects in multiple-frame bridges. Maragakis et al. [8] investigated the effects of energy losses when the bridge deck collides with the abutment. Various damper elements were placed on the abutment to account for the energy dissipation during the pounding action. Many parameters, such as coefficient of restitution, abutment and deck stiffness, gap, and deck to abutment mass ratio, have been studied to prove that the pounding effect plays an important disadvantageous role in the seismic action on bridges with flexural abutments. Guo et al. [9] presented an experimental and analytical study on the pounding reduction of highway bridges subjected to seismic excitations by using magnetorheological dampers. However, the aforementioned references do not consider the effects of spatial variation of the earthquake ground motions on the impact between the girder and the abutment. Bi et al. [10] found that the minimum gap should be provided to avoid the pounding at the abutments and between the girders. Nevertheless, if the expansion joint between 
the abutment and the girder is too large, it may disturb the comfortable experience of drivers and passengers. Therefore, the pounding interaction between the abutment and the girder subjected to the uniform and nonuniform excitations should be systematically investigated.

Prior to conducting the impact analysis, a rational impact model is essential to reflect the physical collision scenario. There exist many pounding models which have been presented to account for the impact effect between adjacent structures in the past several decades. Muthukumar and DesRoches [11] gave the cogency of various impact models in capturing the impact response of neighboring structures. Four impact models, namely, the contact force-based linear spring model, the Kelvin model, the Hertz model, and the restitution-based stereomechnical model, have been widely utilized in the pounding analysis. However, the four impact models do not well model the performance response of the collision between the girder and the abutment when the bridge is subjected to intensive earthquakes. It is worth noting that the axial stiffness between the girder and the abutment, which is a critical parameter in the impact model, is associated with the material properties of the backfill. An approximate stiffness is proposed based on many large-scale abutment tests $[12,13]$.

The spatial variations include three aspects $[14,15]:(1)$ local site effects caused from the variation by filtering effects of overlying soil columns; (2) wave passage, where the nonvertical waves arrive at different points of the ground surface at different times; (3) geometric incoherence results in the scattering in the heterogeneous ground. The numerical simulation of spatial variations is imperative because the asynchronous ground motions can significantly affect the pounding responses of the abutment. The nonstationary conditional simulation approach presented by Vanmarcke et al. [16] is widely used by many researchers due to its simplicity. Therefore, this approach is utilized in this study to generate the earthquake ground motions at each support of the continuous bridge.

The primary objective of this study is to investigate the pounding interaction between the abutment and the steel girder subjected to the uniform and nonuniform excitations with different wave propagation speeds. An elastic-perfectly plastic element is used to simulate the nonlinear rubber bearings. A trilinear impact model based on experimental data is adopted to simulate the pounding effects between the abutment and the girder. The FE model is established in the package Open System for Earthquake Engineering Simulation (OpenSees). The steel girder and the reinforced concrete piers are modeled by nonlinear displacement-based fiber elements. The nonstationary conditional simulation is performed to generate the asynchronous ground motions. A real two-span continuous steel box girder bridge is taken as the example to analyze and assess the pounding interaction between the abutment and the girder. The comparisons of the pounding forces, the shear forces of nonlinear bearings, the moments of reinforced concrete piers, and axial pounding stresses of the steel girder are studied. The made observations indicate that the nonuniform excitation for multisupport bridge is imperative in the analysis and evaluation of

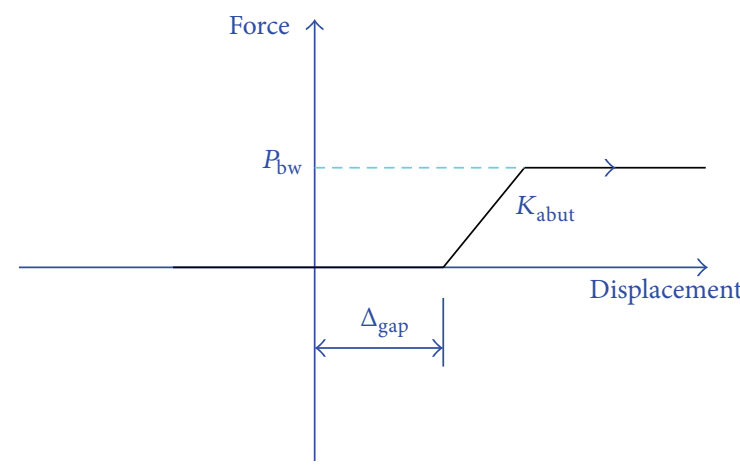

FIGURE 1: Force-deflection relationship of the abutments.

the pounding effects of the highway bridges for it always results in disadvantageous load case.

\section{Impact Interactions between Abutment and Steel Girder}

2.1. Impact Model. Several impact models have been presented by many researchers [17]. However, the impact mechanism between the abutment and the girder is not similar to collision between two rigid or elastic bodies completely. Therefore, Clatrans [18] recommended a trilinear approximation of the force-deformation relationship to simulate the longitudinal response of seat abutment; see Figure 1. The trilinear model consists of three segments: (i) a zero stiffness segment, which accounts for the expansion gap; (ii) a realistic stiffness segment of the embankment fill response; and (iii) a yielding stage segment with ultimate longitudinal force capacity $P_{\mathrm{bw}}$. The stiffness of the abutment $K_{\text {abut }}(\mathrm{kN} / \mathrm{m})$ can be given by

$$
K_{\mathrm{abut}}=K_{i} \times w_{\mathrm{bw}} \times\left(\frac{h_{\mathrm{bw}}}{1.7}\right), \quad K_{i} \approx 28.7 .
$$

The passive pressure force resisting the moment at the abutment is expressed as

$$
P_{\mathrm{bw}}=A_{e} \times 239 \times\left(\frac{h_{\mathrm{bw}}}{1.7}\right),
$$

where $w_{\mathrm{bw}}$ and $h_{\mathrm{bw}}$ are projected width and height of the back wall for seat abutment, respectively. The area of a seat abutment is

$$
A_{e}=h_{\mathrm{bw}} \times w_{\mathrm{bw}} .
$$

It is noted that the initial stiffness $K_{i}$ for embankment fill material should meet the requirements of the Caltrans Standard Specifications. For clarity, the contact force based on the bilinear model can be formulated as

$$
\begin{aligned}
& F_{c}=0 \quad u_{i}-u_{j}-g_{p} \leq 0, \\
& F_{c}=K_{\mathrm{abut}} \times\left(u_{i}-u_{j}-g_{p}\right) \quad 0<u_{i}-u_{j}-g_{p} \leq \frac{P_{\mathrm{bw}}}{K_{\mathrm{abut}}}, \\
& F_{c}=P_{\mathrm{bw}} \quad u_{i}-u_{j}-g_{p}>\frac{P_{\mathrm{bw}}}{K_{\mathrm{abut}}},
\end{aligned}
$$


where $F_{c}$ is contact force; $u_{i}$ and $u_{j}$ are displacements of pounding nodes $i$ and $j$, respectively; $g_{p}$ is the distance of the gap.

2.2. Simulation on Ground Motion. The out-of-phase effect on the pounding of adjacent girder and the abutment is mainly investigated in this paper. Therefore, as one of the primary factors resulting in the inhomogeneous phenomenon at different supports of the bridge, the spatial variation of seismic waves is an imperative issue required to be solved. Three factors may affect the spatial variations of seismic ground motion, the wave passage effect, the incoherence effect, and the local site effect [19]. Many researchers have presented several solutions for this critical issue $[16,20,21]$. Among these approaches, the conditional simulation of a nonuniform seismic ground motion field based on nonstationary theory developed by Vanmarcke et al. [16] is adopted in this study due to its simplicity. This critical principle of the method is concisely introduced in the following paragraph.

Let us consider a segment of the ground motion at a point $x_{i}$ and assume it can be represented by a nonergodic, zero-mean, homogeneous, mean-square continuous space time process $Z_{i}(t)$. The process $Z_{i}(t)$ can be expressed as a sum of independent frequency-specific spatial processes in consecutive constant-size frequency intervals as follows:

$$
\begin{gathered}
Z_{i}(t)=\sum_{k=1}^{K}\left[A_{i k} \cos \left(\omega_{k} t\right)+B_{i k} \sin \left(\omega_{k} t\right)\right], \\
\omega_{k}=(k-1) \Delta \omega \quad(k=1,2, \ldots K), \\
\Delta \omega=\frac{2 \pi}{t_{f}+\Delta t},
\end{gathered}
$$

where the coefficients $A_{i k}$ and $B_{i k}$ are zero-mean random variables; $t_{f}$ is the length of the process. For a discrete-time process, defined at times

$$
\begin{aligned}
t_{j} & =(j-1) \Delta t \quad(k=1,2, \ldots K), \\
\Delta t & =\frac{t_{f}}{K-1},
\end{aligned}
$$

the coefficients $A_{i k}$ and $B_{i k}$ are related to $Z_{i}\left(t_{j}\right)$ through the discrete Fourier Transform,

$$
\begin{gathered}
A_{i k}=\frac{1}{K} \sum_{j=1}^{K} Z_{i}\left(t_{j}\right) \cos \left(\frac{2 \pi(k-1)(j-1)}{K}\right), \\
B_{i k}=\frac{1}{K} \sum_{j=1}^{K} Z_{i}\left(t_{j}\right) \sin \left(\frac{2 \pi(k-1)(j-1)}{K}\right) .
\end{gathered}
$$

The following symmetry conditions about the Nyquist frequency, $\omega_{1+K / 2}=\pi / \Delta t$, apply to the Fourier coefficients $A_{i k}$ and $B_{i k}$ when the process $Z_{i}(t)$ is real:

$$
\begin{gathered}
A_{i k}=A_{i(K-k+2)}, \\
B_{i k}=-B_{i(K-k+2)}, \\
k=2,3, \ldots, 1+\frac{K}{2} .
\end{gathered}
$$

It is shown that the covariance between coefficients at points $x_{i}$ and $x_{j}, C_{i j}\left(\omega_{k}\right)$, can be written as [22]

$$
\begin{aligned}
& C_{i j}\left(\omega_{k}\right) \\
& =E\left(A_{i k} A_{j k}\right) \\
& =\left\{\begin{array}{cl}
\frac{1}{2} \rho_{\omega_{k}}\left(\gamma_{i j}\right) G\left(\omega_{k}\right) \Delta \omega, & \text { for } k=1, \\
\frac{1}{4}\left\{\rho_{\omega_{k}}\left(\gamma_{i j}\right) G\left(\omega_{k}\right)\right. & \\
\left.\quad+\rho_{\omega_{K-k+2}}\left(\gamma_{i j}\right) G\left(\omega_{K-k+2}\right)\right\} \Delta \omega, & \text { for } k=2, \ldots, \frac{K}{2}, \\
\rho_{\omega_{k}}\left(\gamma_{i j}\right) G\left(\omega_{k}\right) \Delta \omega, & \text { for } k=\frac{K}{2}+1,
\end{array}\right.
\end{aligned}
$$$$
\gamma_{i j}=x_{i}-x_{j}
$$

where $\gamma_{i j}$ is the relative position vector, $G(\omega)$ is the onesided "point" spectral density function, and $\rho_{\omega_{k}}\left(\gamma_{i j}\right)$ is the frequency-dependent spatial correlation function. Note that

$$
E\left(A_{i k} A_{j k}\right)=E\left(B_{i k} B_{j k}\right)=C_{i j}\left(\omega_{k}\right) \quad \text { for } k=2, \ldots, \frac{K}{2} .
$$

The spatially correlated ground motions can then be obtained by the following steps: (i) generate sets of Fourier coefficients $A_{i k}$ and $B_{i k}$, for each frequency $\omega_{k}(k=1,2, \ldots 1+K / 2)$; (ii) obtain the remainder using the symmetry conditions in (3); and (iii) use the Fast Fourier Transform algorithm to perform the inverse discrete transform.

Consider the simulation of seismic ground motions at a set of $m$ target points $x_{\beta}$, given that some motions have been recorded at a set of $n=N-m$ measurement points, where $N$ is the total number of points. The covariance matrix, $C_{k}=$ $\left[C_{i j}\left(\omega_{k}\right)\right](i, j=1,2, \ldots, n+m)$, for each Fourier frequency $\omega_{k}(k=1,2, \ldots, 1+K / 2)$ can be assembled and expressed as

$$
C_{k}=\left[\begin{array}{ll}
C_{\alpha \alpha} & C_{\alpha \beta} \\
C_{\alpha \beta}^{T} & C_{\beta \beta}
\end{array}\right] .
$$

Assume a set of simulated Fourier coefficients

$$
A_{s}=\left\{A_{s \alpha}, A_{s \beta}\right\},
$$

where $A_{s \alpha}$ and $A_{s \beta}$ denote the coefficients at recording and target points, respectively. A set of simulated Fourier coefficients $B_{s}$ can be defined in the same way. To simulate $A_{s}$ and $B_{s}$, the covariance matrix $C_{k}$ is evaluated for frequencies up to $\omega_{1+K / 2}=\pi / \Delta t$. For admissible spatial correlation and spectral density functions, $C_{k}$ is positive definite and can be expressed as the product of a nonsingular lower triangular matrix, $L_{k}$, and its transpose by means of the Cholesky decomposition

$$
C_{k}=L_{k} L_{k}^{T}
$$


In case the limited-duration segment of the ground motion can be modelled as a Gaussian process, two sets of independent standard normal random variables can be simulated for each frequency:

$$
\begin{aligned}
& U_{k}=\left\{U_{1 k}, U_{2 k}, \ldots U_{N k}\right\}, \\
& V_{k}=\left\{V_{1 k}, V_{2 k}, \ldots V_{N k}\right\} .
\end{aligned}
$$

Sets $A_{s}$ and $B_{s}$ are then generated by

$$
\begin{aligned}
& A_{s}=L_{k} U_{k}, \\
& B_{s}=L_{k} V_{k} .
\end{aligned}
$$

It is easy to see that $A_{s}$ and $B_{s}$ have the proper covariance structure. Based on the subsets of simulation values at the recording points, $A_{s \alpha}$ and $B_{s \alpha}$, the linear prediction estimators at the target points are given by

$$
\begin{aligned}
& A_{s \beta}^{*}=C_{\alpha \beta}^{T} C_{\alpha \alpha}^{-1} A_{s \alpha}, \\
& B_{s \beta}^{*}=C_{\alpha \beta}^{T} C_{\alpha \alpha}^{-1} B_{s \alpha} .
\end{aligned}
$$

The conditional simulation now involves generating for each frequency $\omega_{k}$ sets of Fourier coefficients $A_{s c, k}$ and $B_{s c, k}$ at target points $x_{\beta}$, according to the conditional simulation algorithm

$$
\begin{aligned}
A_{s c, k} & =\left\{A_{\beta}^{*}+A_{s \beta}-A_{s \beta}^{*}\right\}_{(k)}, \\
B_{s c, k} & =\left\{B_{\beta}^{*}+B_{s \beta}-B_{s \beta}^{*}\right\}_{(k)},
\end{aligned}
$$

where $A_{\beta}^{*}$ and $B_{\beta}^{*}$ are the linear prediction estimators based on the observed Fourier coefficients at the recording points $A_{\alpha}$ and $B_{\alpha}$ :

$$
\begin{aligned}
A_{\beta}^{*} & =C_{\alpha \beta}^{T} C_{\alpha \alpha}^{-1} A_{\alpha}, \\
B_{\beta}^{*} & =C_{\alpha \beta}^{T} C_{\alpha \alpha}^{-1} B_{\alpha} .
\end{aligned}
$$

The remaining Fourier coefficients at frequency $\omega_{k}(k=$ $2+K / 2, \ldots, K)$ are then obtained using the symmetry conditions. Once coefficients have been generated for the entire frequency range, an inverse FFT can be applied to yield a set of ground motion time histories at the target points. The conditional simulation of seismic ground motions is displayed in Figure 2.

2.3. Equation of Motion for Pounding Action. For a lumped mass system, the dynamic equilibrium equation in terms of the nonuniform excitation can be written as

$$
\begin{gathered}
{\left[\begin{array}{cc}
\mathbf{M}_{s s} & \mathbf{0} \\
\mathbf{0} & \mathbf{M}_{b b}
\end{array}\right]\left\{\begin{array}{l}
\ddot{\mathbf{u}}_{s}^{t} \\
\ddot{\mathbf{u}}_{b}^{t}
\end{array}\right\}+\left[\begin{array}{ll}
\mathbf{C}_{s s} & \mathbf{C}_{s b} \\
\mathbf{C}_{b s} & \mathbf{C}_{b b}
\end{array}\right]\left\{\begin{array}{l}
\dot{\mathbf{u}}_{s}^{t} \\
\dot{\mathbf{u}}_{b}^{t}
\end{array}\right\}} \\
+\left[\begin{array}{ll}
\mathbf{K}_{s s} & \mathbf{K}_{s b} \\
\mathbf{K}_{b s} & \mathbf{K}_{b b}
\end{array}\right]\left\{\begin{array}{l}
\mathbf{u}_{s}^{t} \\
\mathbf{u}_{b}^{t}
\end{array}\right\}+\left[\begin{array}{ll}
\mathbf{K}_{s s}^{p} & \mathbf{K}_{s b}^{p} \\
\mathbf{K}_{b s}^{p} & \mathbf{K}_{b b}^{p}
\end{array}\right]\left\{\begin{array}{l}
\mathbf{d}_{s}^{p} \\
\mathbf{d}_{b}^{p}
\end{array}\right\}=\left\{\begin{array}{l}
\mathbf{0} \\
\mathbf{0}
\end{array}\right\},
\end{gathered}
$$

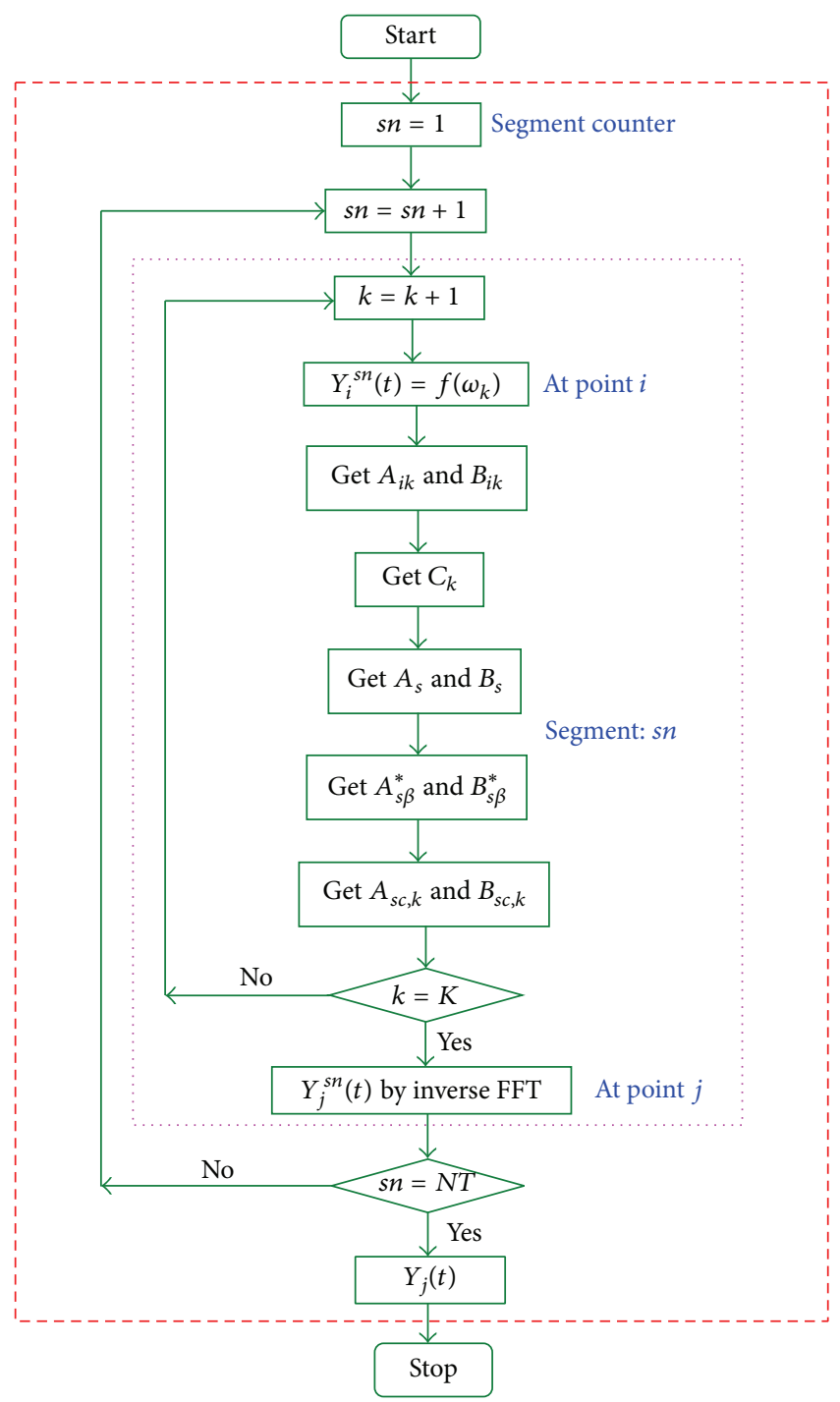

FIGURE 2: Flowchart of conditional simulation.

where the subscript $s$ and $b$ denote the superstructure and base foundation, respectively; $\mathbf{M}_{s s}$ and $\mathbf{M}_{b b}$ are the lumped mass matrices of the superstructure and foundation, respectively; $\mathbf{C}_{s s}, \mathbf{C}_{s b}, \mathbf{C}_{b s}$, and $\mathbf{C}_{b b}$ are damping matrices, respectively, in terms of damping of superstructure and foundation; similarly, $\mathbf{K}_{s s}, \mathbf{K}_{s b}, \mathbf{K}_{b s}$, and $\mathbf{K}_{b b}$ are the matrices with respect to stiffness of the superstructure and the foundation, respectively; I is the earthquake influence coefficient vector; $\ddot{\mathbf{u}}_{s}^{t}$ and $\ddot{\mathbf{u}}_{b}^{t}$ are the absolute acceleration vector of the superstructure and the foundation, respectively; $\dot{\mathbf{u}}_{s}^{t}$ and $\dot{\mathbf{u}}_{b}^{t}$ are the absolute velocity vectors of the superstructure and the foundation, respectively; $\mathbf{u}_{s}^{t}$ and $\mathbf{u}_{b}^{t}$ are the absolute displacement matrices of the superstructure and the foundation, respectively; $\mathbf{K}_{s s}^{p}$ are the stiffness matrix of the partial superstructure where the impact occurs; $\mathbf{K}_{s b}^{p}$ and $\mathbf{K}_{b s}^{p}$ are the stiffness matrices of the coupled part of the superstructure and the foundation where the pounding occurs; $\mathbf{K}_{b b}^{p}$ are the stiffness matrix of foundation at which the impact occurs; $\mathbf{d}_{s}^{p}$ and $\mathbf{d}_{b}^{p}$ are the relative displacement matrices between 


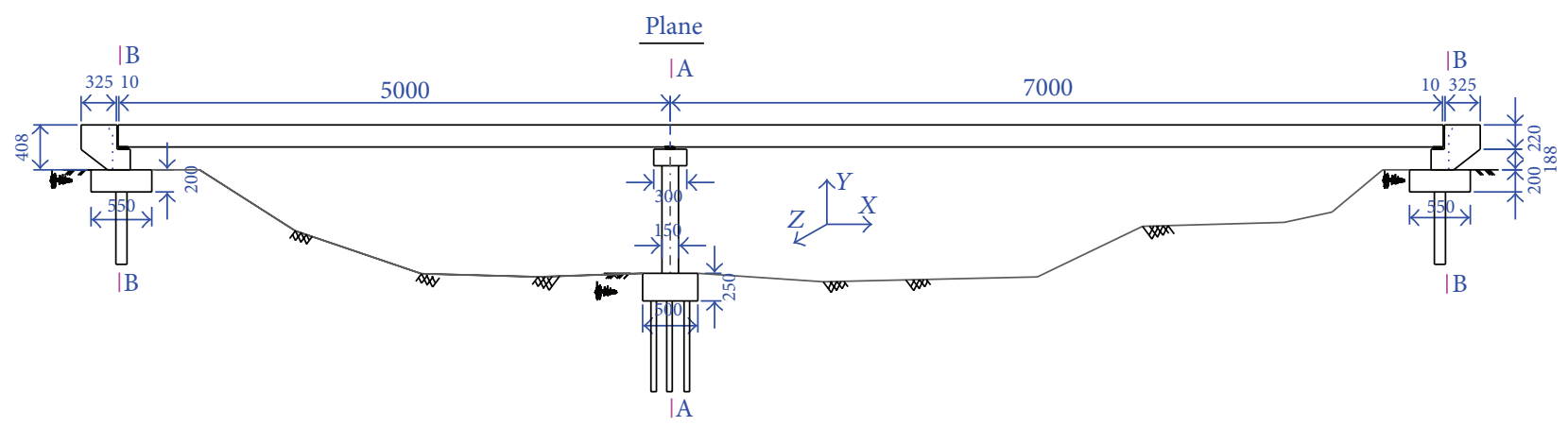

(a) Profile of a two-span steel continuous girder bridge (unit: $\mathrm{cm}$ )

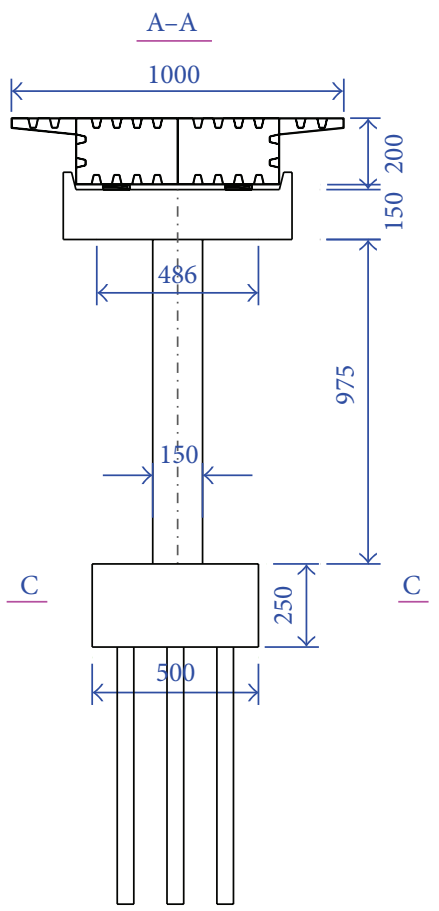

(b) Detailed cross section of the pier and abutment (unit: $\mathrm{cm}$ )

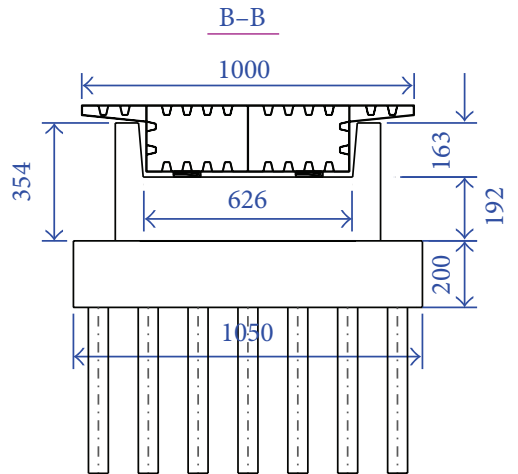

(c) Detailed cross section of a pier (unit: $\mathrm{mm}$ )

FIGURE 3: Profile of a steel continuous girder bridge.

adjacent components located in the superstructure and the foundation, respectively.

It is noted that the pounding scenario which generates high magnitude and short duration acceleration pulse during an earthquake will make the numerical convergence difficult. Therefore, a variable time stepping procedure is utilized to determine the impact time and solve the equation of motion.

\section{Pounding Effect of the Bridge}

3.1. Structural Description. To assess the pounding interaction between the girder and the abutment subjected to the nonuniform seismic excitations, a real two-span continuous steel girder bridge constructed in China is selected as an example. The bridge is supported on reinforced concrete piers and the two spans are $50 \mathrm{~m}$ and $70 \mathrm{~m}$, respectively, as shown in Figure 3(a). The detailed profile of the pier and the abutment

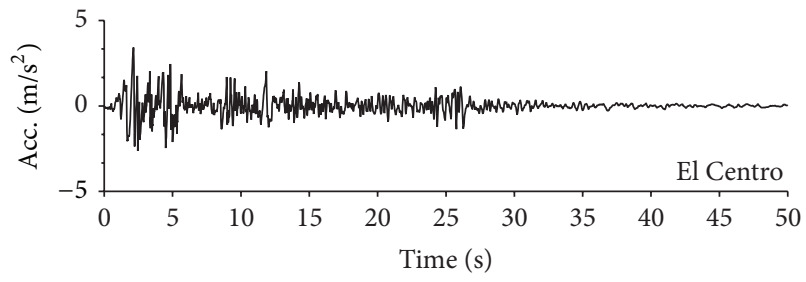

FIgure 4: Original time histories of El Centro (NS).

is displayed in Figure 3(b) and the reinforcement details of a pier section are shown in Figure 3(c). The longitudinal, transversal, and vertical directions are denoted by $X, Y$, and $Z$, respectively. The bridge pier consists of single square column and the cross-sectional area is $2.25 \mathrm{~m}^{2}$. The clear height of the column is $9.75 \mathrm{~m}$. The rubber bearings are placed 

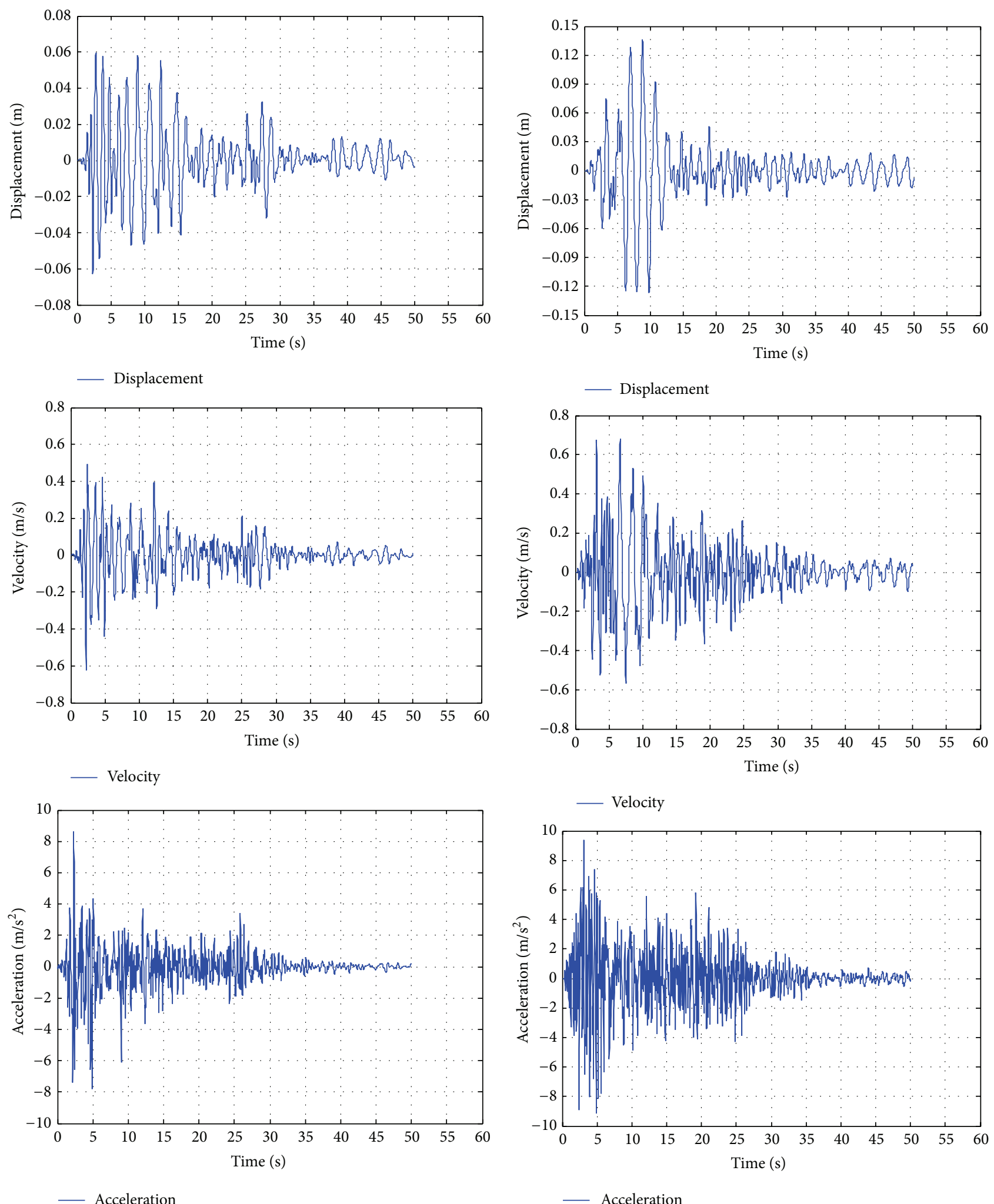

_ Acceleration

(b) Right abutment

(a) Left abutment

Figure 5: Dynamic responses of abutments $\left(V_{w}=400 \mathrm{~m} / \mathrm{s}\right)$. 

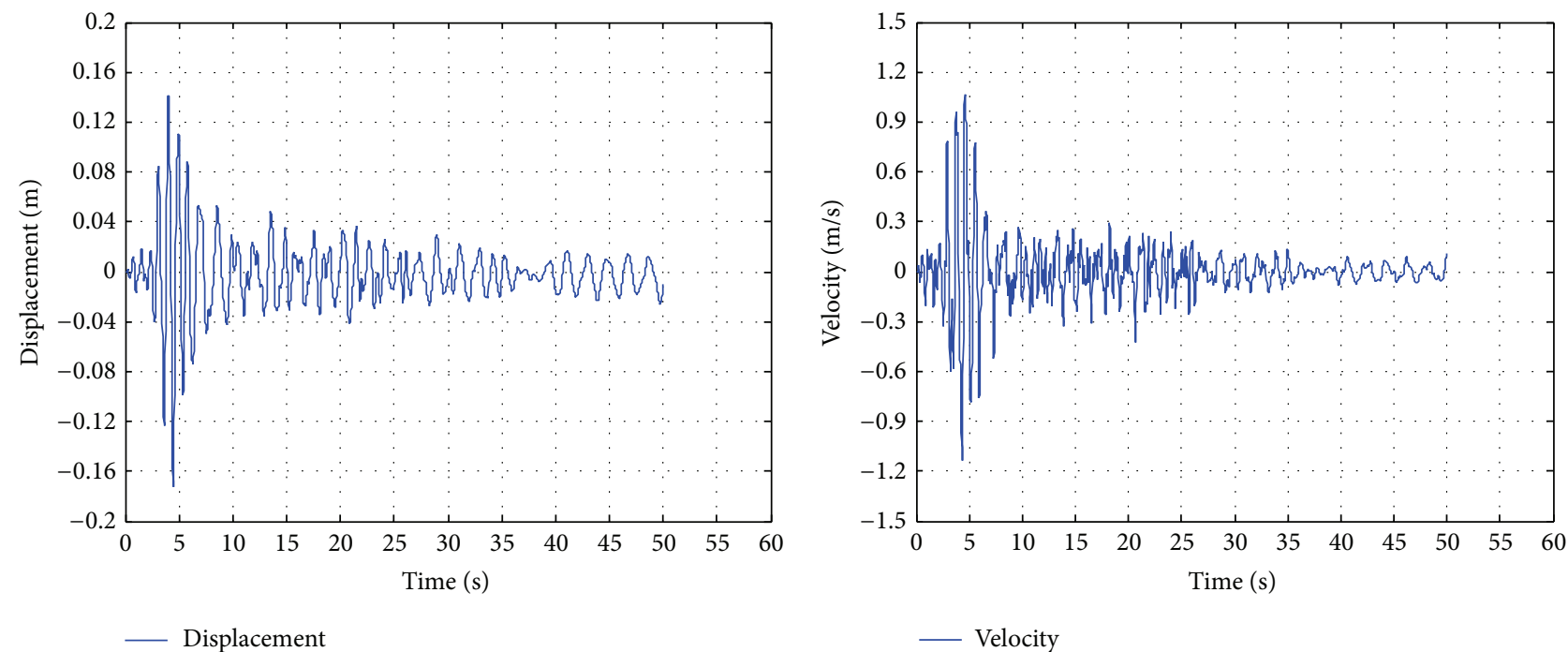

_ Displacement

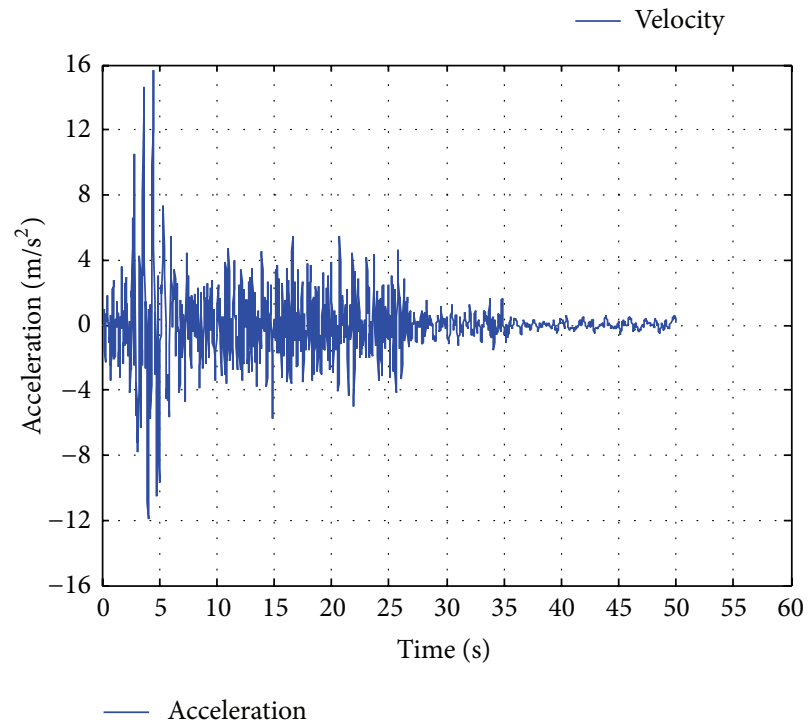

FIgURE 6: Dynamic responses of the middle foundation $\left(V_{w}=400 \mathrm{~m} / \mathrm{s}\right)$.

on the bent cap and the abutments. The space between two rectangular octagonal hoops is $0.4 \mathrm{~m}$. The densities of the steel and the reinforced concrete are 7850 and $2500 \mathrm{~kg} / \mathrm{m}^{3}$, respectively. The diameters of longitudinal and transversal reinforcing bars are $32 \mathrm{~mm}$ and $16 \mathrm{~mm}$, respectively. The yield strength $f_{y}$ of the reinforcing steel is $280 \mathrm{MPa}$. Young's modulus of the steel $E_{s}$ and the concrete $E_{c}$ are $2.0 \times 10^{5} \mathrm{MPa}$ and $3.0 \times 10^{4} \mathrm{MPa}$, respectively. The parameters about the rubber bearing are tabulated in Table 1 . The shear modulus and the height of all the bearings are $1.0 \mathrm{GPa}$ and $0.15 \mathrm{~m}$, respectively. The bearings at left and right abutments have the same size of which the area of cross section and the shear stiffness $\left(K_{h}\right)$ are $0.03 \mathrm{~m}^{2}$ and $209.0 \mathrm{kN} / \mathrm{m}$, respectively. The counterparts of the bearing at middle bent cap are $0.126 \mathrm{~m}^{2}$ and $838.0 \mathrm{kN} / \mathrm{m}$, respectively. The yielding strengths of two types of bearing are $20.9 \mathrm{kN}$ and $83.8 \mathrm{kN}$, respectively.

The FE model of this bridge is established with the aids of the package OpenSees. The steel box girder and the reinforced concrete pier are modeled by using nonlinear fiber elements. The rubber bearings are modeled by using an elastic-perfectly plastic zero-length element. A trilinear zero-length element is used to simulate the impact effects between the abutment and the girder. The dynamic equilibrium equation involved multisupport excitation which can be solved using the Newmarkbeta method with a self-adaptive integration time step from $1.0 \times 10^{-4} \mathrm{~s}$ to $2.0 \times 10^{-2} \mathrm{~s}$ to ensure the numerical convergence at the end of each step. The Rayleigh damping assumption is adopted to construct the structural damping matrix, and the damping ratio of the bridge is set as 0.03 [22-25].

3.2. Conditional Simulation of Ground Motion at Three Support Points. To evaluate the pounding interaction between the girder and the abutment of the continuous steel girder bridge, the El Centro NS (1940) ground motion is selected as inputs to the example bridge structure. The time history of the seismic record is shown in Figure 4. The original peak ground acceleration (PGA) of the seismic record is $3.417 \mathrm{~m} / \mathrm{s}^{2}$. The original time history of the seismic record is scaled to $8.6 \mathrm{~m} / \mathrm{s}^{2}$ to perform the pounding analysis. Three scenarios are taken into consideration to investigate the pounding effects under 

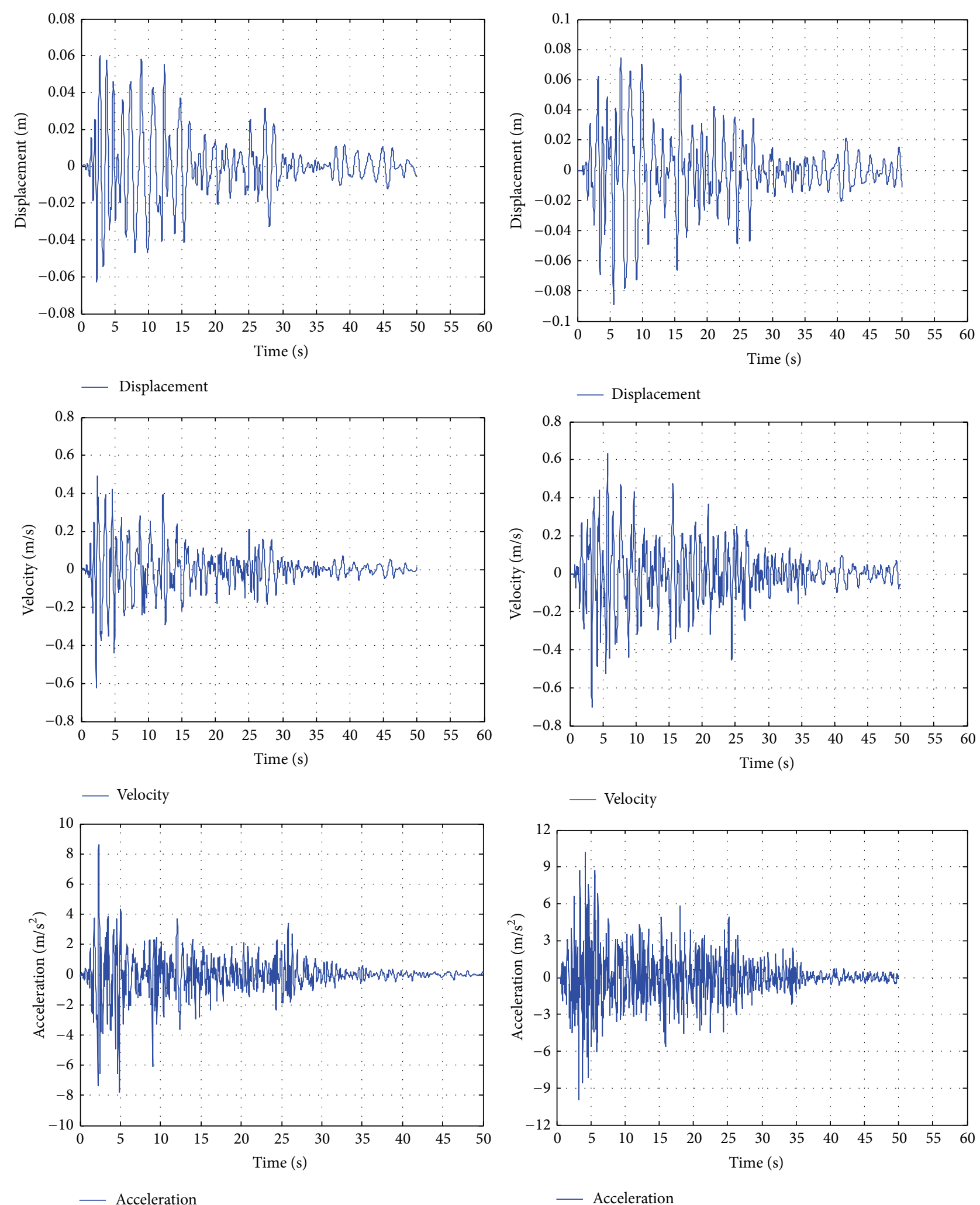

Figure 7: Dynamic responses of abutments $\left(V_{w}=200 \mathrm{~m} / \mathrm{s}\right)$. 

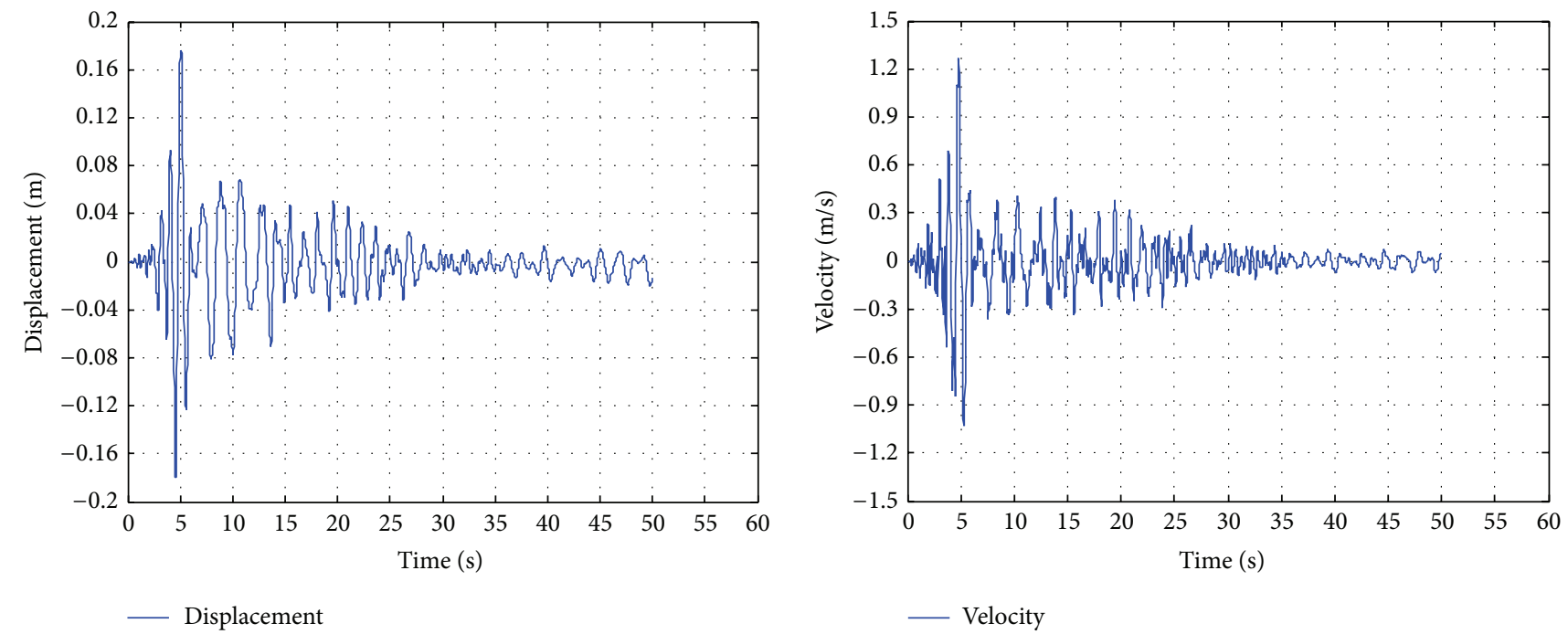

— Displacement

— Velocity

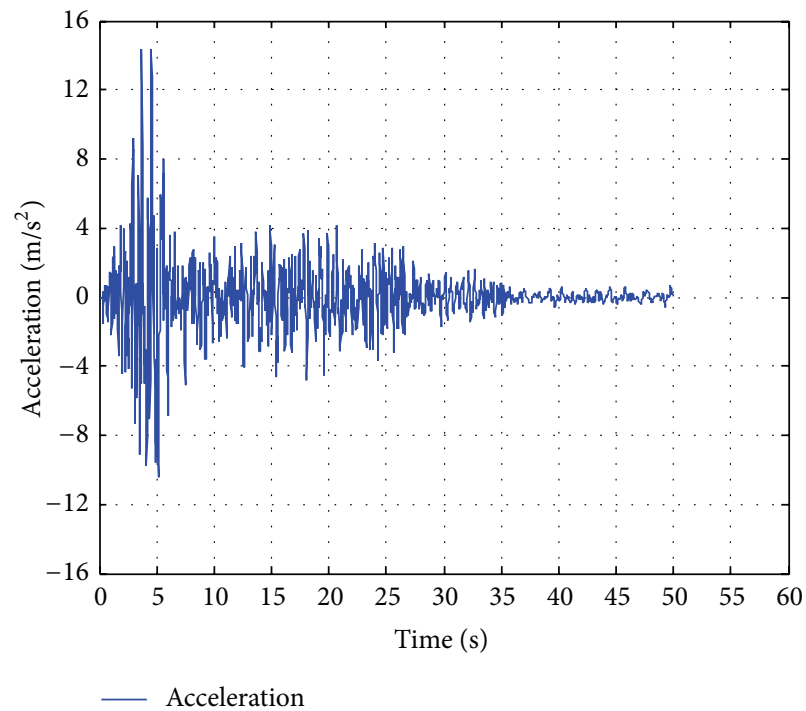

Figure 8: Dynamic responses of the middle foundation $\left(V_{w}=200 \mathrm{~m} / \mathrm{s}\right)$.

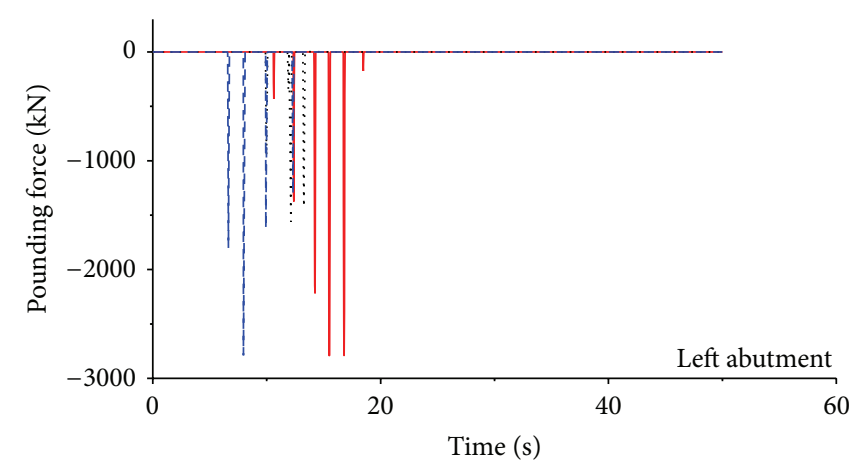

..... Nonuniform $(200 \mathrm{~m} / \mathrm{s})$ - Uniform - - - Nonuniform $(400 \mathrm{~m} / \mathrm{s})$

(a) Left abutment

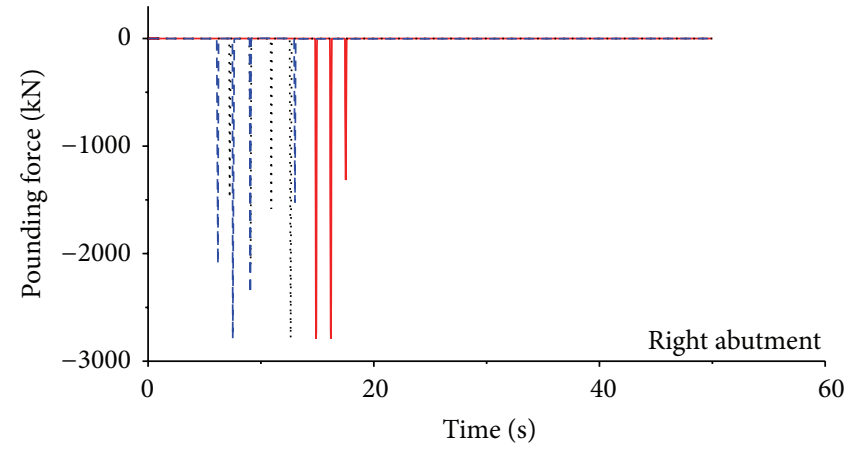

… Nonuniform $(200 \mathrm{~m} / \mathrm{s})$ - Uniform - - - Nonuniform $(400 \mathrm{~m} / \mathrm{s})$

(b) Right abutment

FIGURE 9: Time history of pounding force at abutments. 


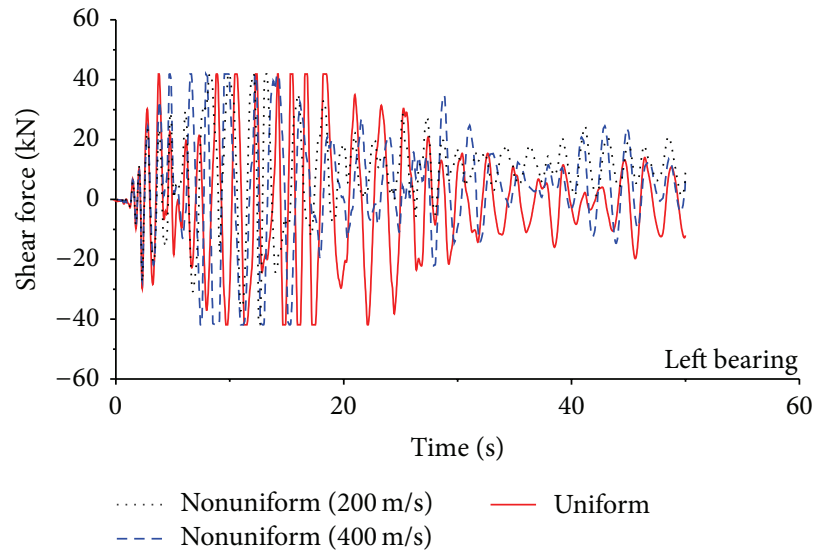

(a) Left bearing

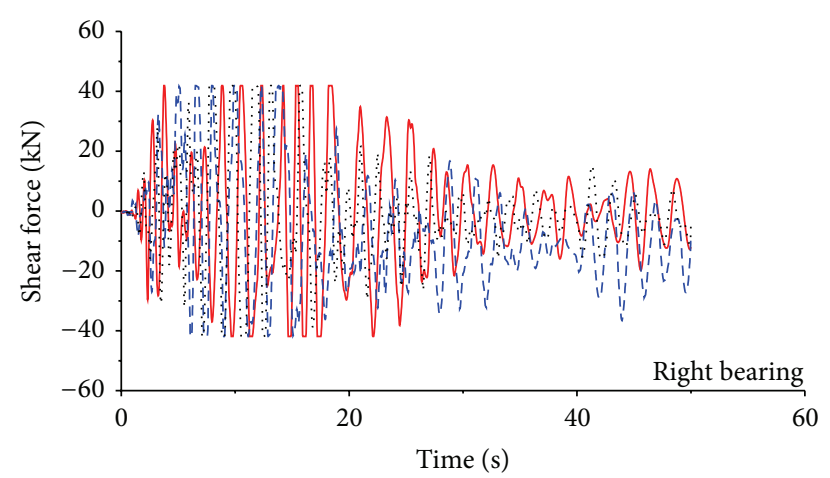

.... Nonuniform $(200 \mathrm{~m} / \mathrm{s}) \quad$ Uniform

(b) Right bearing
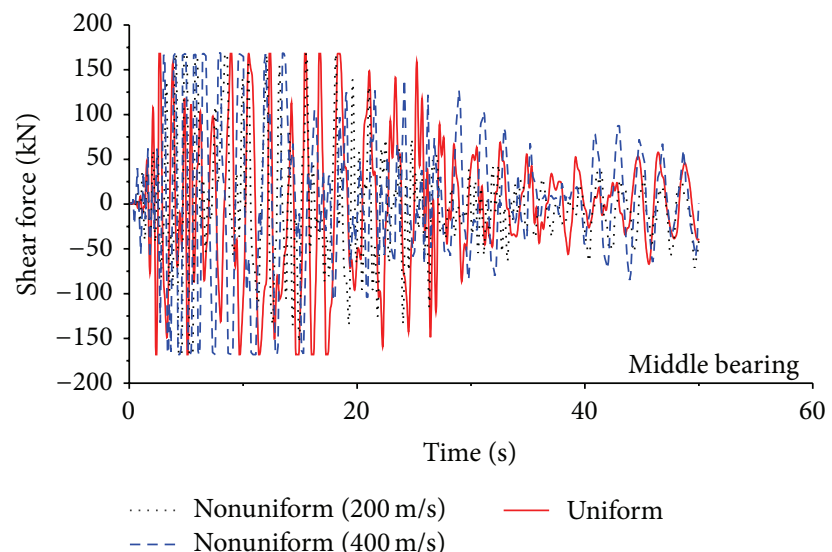

(c) Middle bearing

Figure 10: Time history of shear force of bearings.

TABLE 1: Bearing properties.

\begin{tabular}{lccccc}
\hline Location of bearings & $G(\mathrm{kPa})$ & $A\left(\mathrm{~m}^{2}\right)$ & $h(\mathrm{~m})$ & $K_{h}=\mathrm{GA} / h(\mathrm{kN} / \mathrm{m})$ & Yielding strength $(\mathrm{kN})$ \\
\hline Left abutment & $1.0 \times 10^{3}$ & 0.03 & 0.15 & 209.0 & 20.9 \\
Middle pier cap & $1.0 \times 10^{3}$ & 0.126 & 0.15 & 838.0 & 83.8 \\
Right abutment & $1.0 \times 10^{3}$ & 0.03 & 0.15 & 209.0 & 20.9 \\
\hline
\end{tabular}

both uniform and nonuniform excitations with two wave propagation velocities $V_{w}$, namely, $200 \mathrm{~m} / \mathrm{s}$ and $400 \mathrm{~m} / \mathrm{s}$. The simulated acceleration time histories at three supports of the bridge are indicated in Figures 5, 6, 7, and 8, respectively, for the two wave propagation velocities. In the simulation of the ground motion, the frequency-dependent spatial correlation function of phase-aligned ground acceleration presented by Harichandran and Vanmarcke [26] is adopted:

$$
\begin{gathered}
\rho_{\omega_{k}}\left(\gamma_{i j}\right)=0.736 e^{-0.536\left(\left|\gamma_{i j}\right| / \theta_{\omega}\right)}+0.264 e^{-0.744\left(\left|\gamma_{i j}\right| / \theta_{\omega}\right)}, \\
\theta_{\omega}=5210\left\{1+\left(\frac{\omega}{2.17 \pi}\right)^{2.78}\right\}^{-1 / 2},
\end{gathered}
$$

where $\theta_{\omega}$ is the frequency-dependent scale of the fluctuation. In addition, it is noted that the ground motion used in the computation is divided into five segments with the time duration of 1.48 s, 4.32 s, 20.8 s, 8.4 s, and 15 s, respectively. Each of the five segments is assumed as a stationary process. Then the five segments are assembled together through the linear interpolation and the wave propagation phase delays are postprocessed. Finally, the velocity and displacement time histories at each support can be calculated by integrating the acceleration time histories with respect to time, respectively.

\section{Seismic Response Analyses}

4.1. Response of Abutment. As discussed above, three scenarios are considered to evaluate the dynamic responses of pounding interaction between the abutment and the steel girder. Figure 9 shows the time histories of pounding forces at the abutment and the peak responses of the pounding force are listed in Table 2. It is seen from Figure 9 and Table 2 
TABle 2: Peak response of pounding force.

\begin{tabular}{lcccccc}
\hline \multirow{2}{*}{ Location } & \multicolumn{2}{c}{ Uniform } & \multicolumn{2}{c}{ Nonuniform $(400 \mathrm{~m} / \mathrm{s})$} & \multicolumn{2}{c}{ Nonuniform $(200 \mathrm{~m} / \mathrm{s})$} \\
& Time $(\mathrm{s})$ & Force $(\mathrm{kN})$ & Time $(\mathrm{s})$ & Force $(\mathrm{kN})$ & Time $(\mathrm{s})$ & 12.12 \\
\hline Left abutment & 15.46 & $2.79 \times 10^{3}$ & 7.96 & $2.79 \times 10^{3}$ & $1.57 \times 10^{3}$ \\
Right abutment & 14.88 & $2.79 \times 10^{3}$ & 7.52 & $2.79 \times 10^{3}$ & 12.62 & $2.79 \times 10^{3}$ \\
\hline
\end{tabular}

TABle 3: Peak responses of shear forces.

\begin{tabular}{|c|c|c|c|c|c|c|}
\hline \multirow{2}{*}{ Location } & \multicolumn{2}{|c|}{ Uniform } & \multicolumn{2}{|c|}{ Nonuniform $(400 \mathrm{~m} / \mathrm{s})$} & \multicolumn{2}{|c|}{ Nonuniform $(200 \mathrm{~m} / \mathrm{s})$} \\
\hline & Time (s) & Force $(\mathrm{kN})$ & Time (s) & Force $(\mathrm{kN})$ & Time (s) & Force $(\mathrm{kN})$ \\
\hline Left bearing & 3.74 & 41.9 & 4.7 & 41.9 & 8.2 & 41.9 \\
\hline Middle bearing & 2.34 & 168.0 & 3.02 & 168.0 & 4.02 & 168.0 \\
\hline Right bearing & 3.74 & 41.9 & 5.08 & 41.9 & 7.10 & 41.9 \\
\hline
\end{tabular}

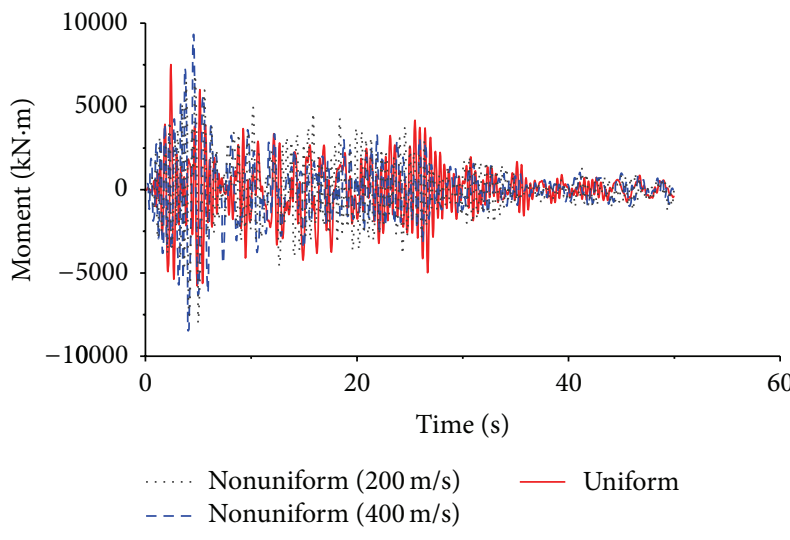

FIGURE 11: Time histories of moment force at the bottom of RC pier.

that the right abutment experienced yielding state under both uniform and nonuniform excitations. The nonuniform excitation with the wave propagation speed of $400 \mathrm{~m} / \mathrm{s}$ is the most critical loading case for the right abutment. The right abutment is the latest one to trigger yielding state when subjected to uniform excitation. However, the left abutment does not reach yielding state in the case of nonuniform excitation with the propagation speed of $200 \mathrm{~m} / \mathrm{s}$. In this case, the peak pounding force is $1.57 \times 10^{3} \mathrm{kN}$ which is much less than that of the right abutment. The comparison between two abutments indicates that the spatial variations of the ground motion should be taken into consideration in the assessment on the pounding effects because it provides the disadvantageous loading excitations.

4.2. Response of Rubber Bearing. Figure 10 displays the time histories of the shear forces of the bearings at the left abutment, the middle bent cap, and the right abutment for the concerned three scenarios. Listed in Table 3 are the peak responses and the time occurrence of shear forces of bearing at three locations. It can be observed that the bearings at the three locations experience the yielding stages for all the three loading cases. As far as one rubber bearing among them is concerned, it yields at first when subjected to the uniform excitation in comparison with the case under the nonuniform
TABLE 4: Peak response of moment force and curvature.

\begin{tabular}{lcc}
\hline Case & Curvature $(1 / \mathrm{m})$ & Moment $(\mathrm{kN} \cdot \mathrm{m})$ \\
\hline Uniform & 0.0026 & $7.51 \times 10^{3}$ \\
Nonuniform $(400 \mathrm{~m} / \mathrm{s})$ & 0.0051 & $9.28 \times 10^{3}$ \\
Nonuniform $(200 \mathrm{~m} / \mathrm{s})$ & 0.0032 & $8.06 \times 10^{3}$ \\
\hline
\end{tabular}

excitation. The three bearings reach the yielding state latest when they are subjected to nonuniform excitation with the wave propagation speed of $200 \mathrm{~m} / \mathrm{s}$.

4.3. Response of Reinforced Concrete Pier. Figure 11 displays the time histories of moment of the pier and Figure 12 indicates the moment versus the curvature relationship of the pier. The peak moment is listed in Table 4 . The curvature and the moment responses at the bottom of the pier are variable with the types of the excitation, of which the nonuniform excitation with wave propagation speed of $400 \mathrm{~m} / \mathrm{s}$ is the most critical case. The most critical peak curvature and moment are $0.0051 \mathrm{l} / \mathrm{m}$ and $9.28 \times 10^{3} \mathrm{kN} \cdot \mathrm{m}$, respectively. The moment versus the curvature hysteretic loop under nonuniform excitation with wave propagation speed of $400 \mathrm{~m} / \mathrm{s}$ is plumper than the other two cases, which indicates that the pier dissipates much energy of the earthquake input. The case of uniform excitation is the one that experienced the smallest damage.

4.4. Response of Steel Box Girder. To be the primary component of the bridge, the steel girder bears the moments induced by various loadings, such as dead load, live load, and temperature load. If the pounding interaction between the girder and the abutment occurs during an earthquake, the axial stress in the girder may increase sharply to induce damage events of the steel girder. The time histories of axial stress at both ends of the girder are computed and displayed in Figure 13. The peak axial stresses are tabulated in Table 5.

The axial stress responses of the steel girder indicate that the most dangerous loading case for both ends of the steel girder is the nonuniform excitation with the wave propagation speed of $400 \mathrm{~m} / \mathrm{s}$. However, the nonuniform excitation 


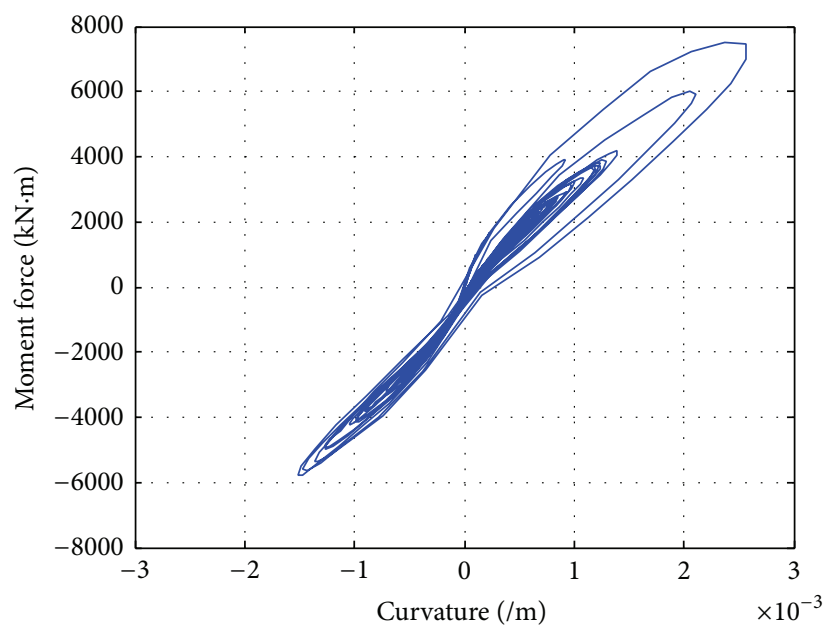

— Uniform

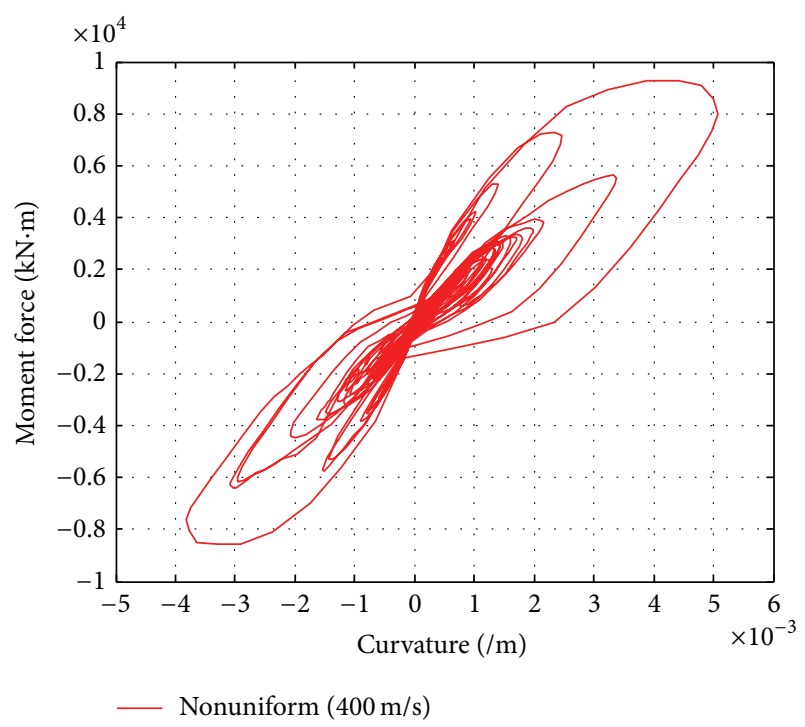

(b)

(a)

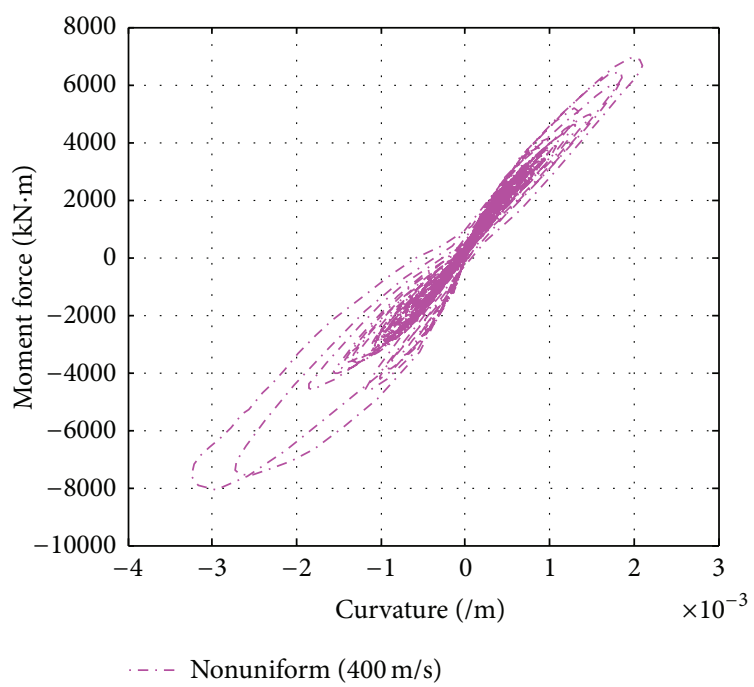

(c)

FIgURE 12: Moment versus curvature relationship of piers.

TABLE 5: Peak response of axial stress of steel girder.

\begin{tabular}{lcccccc}
\hline \multirow{2}{*}{ Location } & \multicolumn{2}{c}{ Uniform } & \multicolumn{2}{c}{ Nonuniform $(400 \mathrm{~m} / \mathrm{s})$} & \multicolumn{2}{c}{ Nonuniform $(200 \mathrm{~m} / \mathrm{s})$} \\
& Time $(\mathrm{s})$ & Stress $(\mathrm{kPa})$ & Time $(\mathrm{s})$ & Stress $(\mathrm{kPa})$ & Time $(\mathrm{s})$ & 1.92 \\
\hline Left end & 15.28 & $8.26 \times 10^{3}$ & 7.78 & $8.39 \times 10^{3}$ & $4.44 \times 10^{3}$ \\
Right end & 16.0 & $8.05 \times 10^{3}$ & 7.34 & $8.96 \times 10^{3}$ & 12.44 & $7.97 \times 10^{3}$ \\
\hline
\end{tabular}

with the wave propagation speed of $200 \mathrm{~m} / \mathrm{s}$ presents the smallest seismic responses.

\section{Concluding Remarks}

The paper investigates the pounding effects between the abutment and the steel girder by considering the uniform and nonuniform excitation with different wave propagation speeds. A detailed nonlinear FE model is established and two types of zero-length nonlinear elements are used to model the pounding interaction between the girder and the abutment and the rubber bearings, respectively. In addition, two types of nonlinear fiber displacement-based elements are used to model the steel box girder and the reinforced concrete pier, respectively. The dynamic analyses on impact effects are 


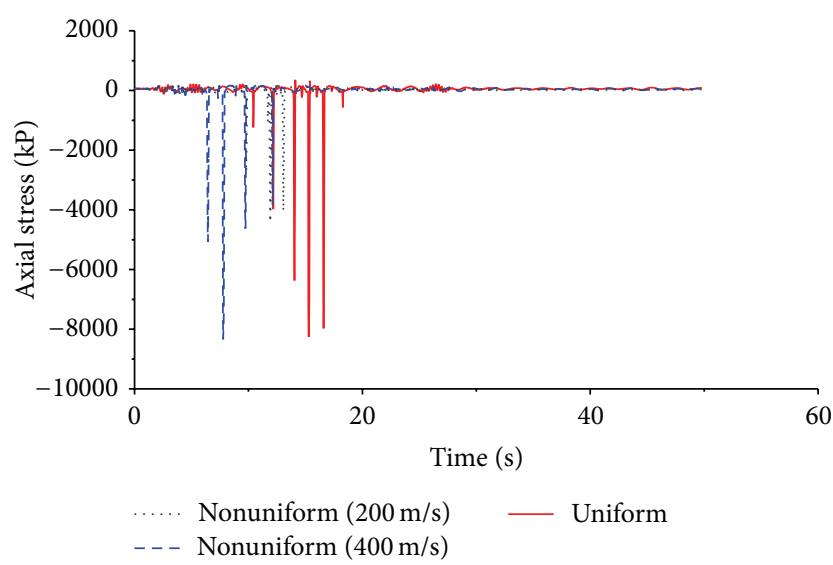

(a) Left end of girder

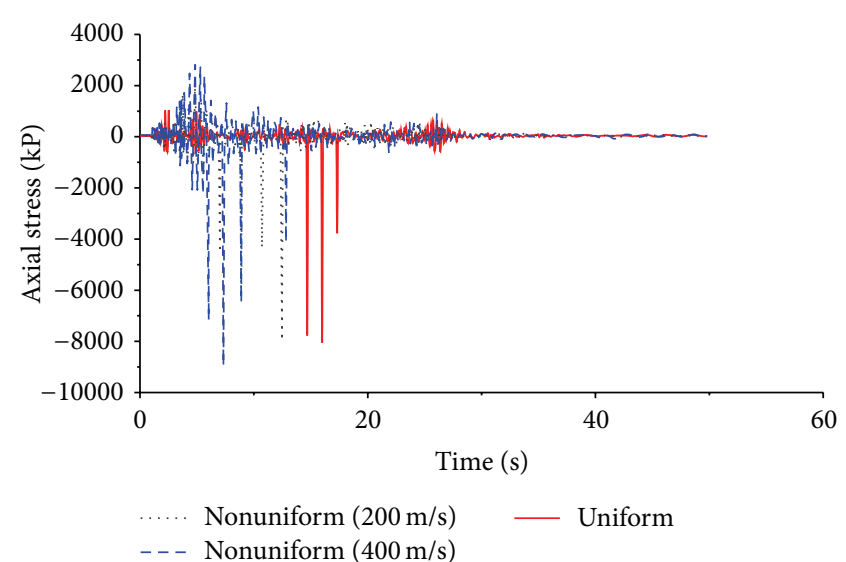

(b) Right end of girder

FIgURE 13: Time history response of axial stress in steel girder.

carried out under the uniform and nonuniform excitations with two wave propagation speeds. The comparison of the seismic responses, such as the pounding force between the abutment and the girder, the shear forces of the rubber bearings, the moments of reinforced concrete pier, and the axial pounding stresses in the steel girder is performed.

The consequence of the comparison indicates that the nonuniform excitation always results in the disadvantageous responses in the seismic analysis of the bridge under impact action.

\section{Conflict of Interests}

The authors declare that there is no conflict of interests regarding the publication of this paper.

\section{Acknowledgments}

The authors are grateful for the financial support from the National Natural Science Foundation of China (51178366), the Technological Project of the Chinese Southern Power Grid Co. Ltd. (K-GD2013-0222), the Fok Ying-Tong Education Foundation (131072), and the Natural Science Foundation of Hubei Province (2014CFA026).

\section{References}

[1] Y. L. Xu, B. Chen, C. L. Ng, K. Y. Wong, and W. Y. Chan, "Monitoring temperature effect on a long suspension bridge," Structural Control and Health Monitoring, vol. 17, no. 6, pp. 632653, 2010

[2] B. Chen, Z. W. Chen, Y. Z. Sun, and S. L. Zhao, "Condition assessment on thermal effects of a suspension bridge based on SHM oriented model and data," Mathematical Problems in Engineering, vol. 2013, Article ID 256816, 18 pages, 2013.

[3] Y. Xia, B. Chen, X.-Q. Zhou, and Y.-L. Xu, "Field monitoring and numerical analysis of Tsing Ma suspension bridge temperature behavior," Structural Control and Health Monitoring, vol. 20, no. 4, pp. 560-575, 2013.
[4] H. Ostuka, S. Unjoh, T. Terayama, J. Hoshikuma, and K. Kosa, "Damage to highway bridges by the 1995 Hyogoken Nanhu earthquake and the retrofit of highway bridges in Japan," in Proceedings of the 3rd U. S. Japan Workshop on Seismic Retrofit of Bridge, Osaka, Japan, December 1996.

[5] B. Chen, Y. Z. Sun, Y. L. Li, and S. L. Zhao, "Control of seismic response of a building frame by using hybrid system with magnetorheological dampers and isolators," Advances in Structural Engineering, vol. 17, no. 8, pp. 1199-1215, 2014.

[6] Earthquake Engineering Research Institute. Northridge Earthquake Reconnaissance Report, vol. 1, Supplement C to vol. 11, April 1995.

[7] R. Desroches and G. L. Fenves, "New design and analysis procedures for intermediate hinges in multiple-frame bridges," Tech. Rep. no. UCB/EERC-97/12, Earthquake Engineering Research Center, University of California, Berkeley, Calif, USA, 1997.

[8] E. Maragakis, B. Douglas, and S. Vrontinos, "Classical formulation of the impact between bridge deck and abutments during strong earthquakes," in Proceedings of the 6th Canadian Conference on Earthquake Engineering, Toronto, Canada, 1991.

[9] A. Guo, Z. Li, H. Li, and J. Ou, "Experimental and analytical study on pounding reduction of base-isolated highway bridges using MR dampers," Earthquake Engineering and Structural Dynamics, vol. 38, no. 11, pp. 1307-1333, 2009.

[10] K. Bi, H. Hao, and N. Chouw, "Required separation distance between decks and at abutments of a bridge crossing a canyon site to avoid seismic pounding," Earthquake Engineering and Structural Dynamics, vol. 39, no. 3, pp. 303-323, 2010.

[11] S. Muthukumar and R. DesRoches, "A Hertz contact model with non-linear damping for pounding simulation," Earthquake Engineering \& Structural Dynamics, vol. 35, no. 7, pp. 811-828, 2006.

[12] B. H. Maroney, Large scale abutment tests to determine stiffness and ultimate strength under seismic loading [Ph.D. dissertation], University of California, Davis, Calif, USA, 1995.

[13] A. Shamsabadi, K. M. Rollins, and M. Kapuskar, "Nonlinear soil-abutment-bridge structure interaction for seismic performance-based design," Journal of Geotechnical and Geoenvironmental Engineering, vol. 133, no. 6, pp. 707-720, 2007.

[14] N. A. Abrahamson, J. F. Schneider, and J. C. Stepp, "Empirical spatial coherency function for application to soil structure 
interaction analysis," Earthquake Spectra, vol. 7, no. 1, pp. 1-27, 1991.

[15] C.-C. Tsai and Y. M. A. Hashash, "Evaluation of two approaches to simulate spatially variable ground motions," Journal of Earthquake Engineering, vol. 14, no. 2, pp. 293-308, 2010.

[16] E. H. Vanmarcke, E. Heredia-Zavoni, and G. A. Fenton, "Conditional simulation of spatially correlated earthquake ground motion," Journal of Engineering Mechanics, vol. 119, no. 11, pp. 2332-2352, 1993.

[17] W. Goldsmith, Impact: The Theory and Physical Behavior of Colliding Solids, Edward Arnold, London, UK, 1960.

[18] California Department of Transportation (CLATRANS), Seismic Design Criteria, Version 1.6, California Department of Transportation (CLATRANS), Sacramento, Calif, USA, 2010.

[19] A. Zerva, "Spatial variability of seismic motions recorded over extended ground surface areas," in Wave Motion in Earthquake Engineering, E. Kausel and G. Manolis, Eds., The MIT Press, Cambridge, Mass, USA, 1999.

[20] G. Deodatis, "Non-stationary stochastic vector processes: seismic ground motion applications," Probabilistic Engineering Mechanics, vol. 11, no. 3, pp. 149-167, 1996.

[21] E. Heredia-Zavoni, On the response of multi-support MDOF systems to spatially varying earthquake ground motion [Ph.D. dissertation], Department of Civil Engineering and Operations Research, Princeton University, 1993.

[22] B. Chen, J. Zheng, and W. Qu, "Control of wind-induced response of transmission tower-line system by using magnetorheological dampers," International Journal of Structural Stability and Dynamics, vol. 9, no. 4, pp. 661-685, 2009.

[23] B. Chen, Y. L. Xu, and X. Zhao, "Integrated vibration control and health monitoring of building structures: a time-domain approach," Smart Structures and Systems, vol. 6, no. 7, pp. 811$833,2010$.

[24] H. N. Li, T. H. Yi, M. Gu, and L. Huo, "Evaluation of earthquakeinduced structural damages by wavelet transform," Progress in Natural Science, vol. 19, no. 4, pp. 461-470, 2009.

[25] T.-H. Yi, H.-N. Li, and M. Gu, "Wavelet based multi-step filtering method for bridge health monitoring using GPS and accelerometer," Smart Structures and Systems, vol. 11, no. 4, pp. 331-348, 2013.

[26] R. S. Harichandran and E. H. Vanmarcke, "Stochastic variation of earthquake ground motion in space and time," Journal of Engineering Mechanics, vol. 112, no. 2, pp. 154-174, 1986. 

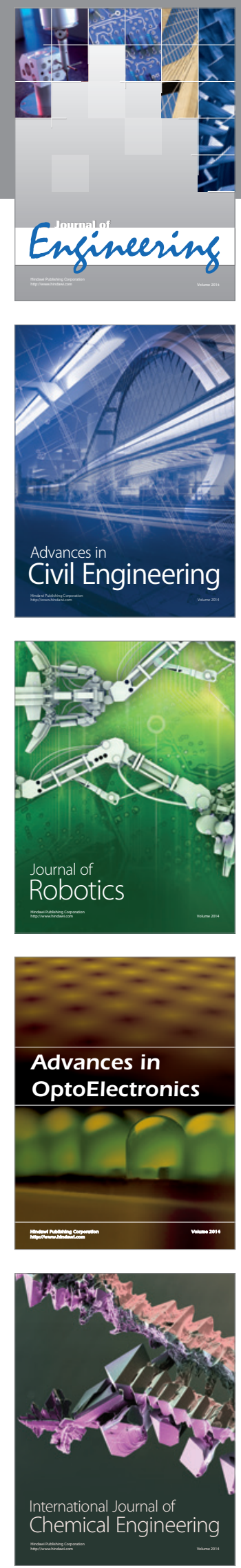

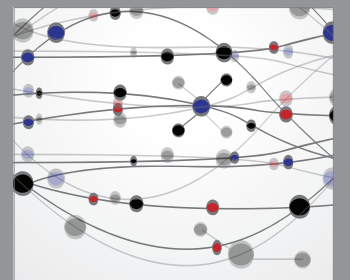

The Scientific World Journal
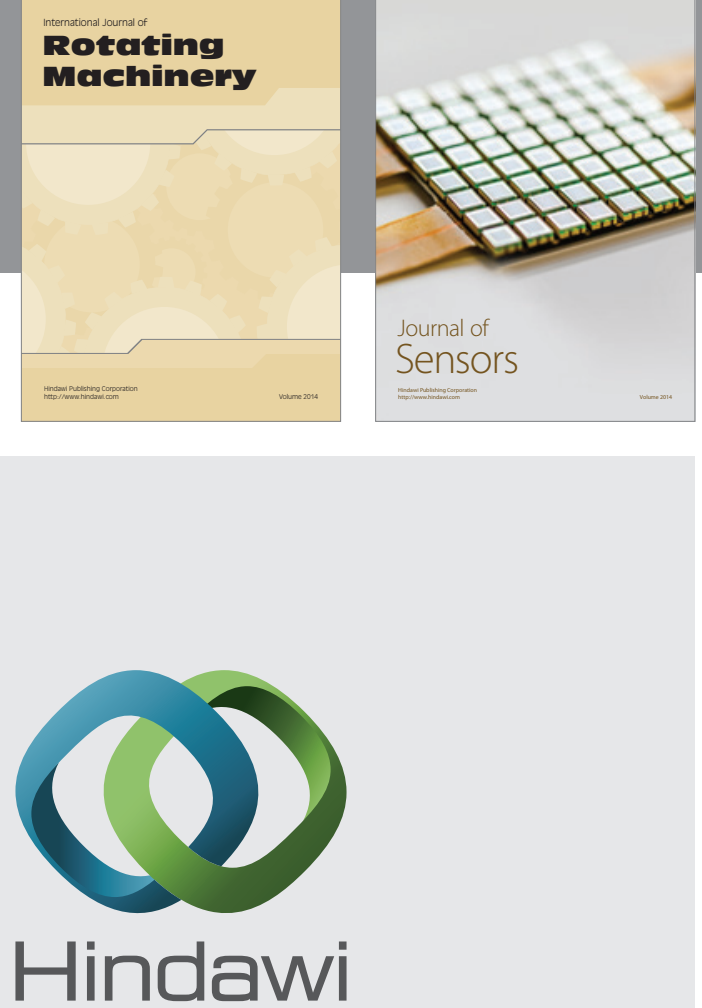

Submit your manuscripts at http://www.hindawi.com
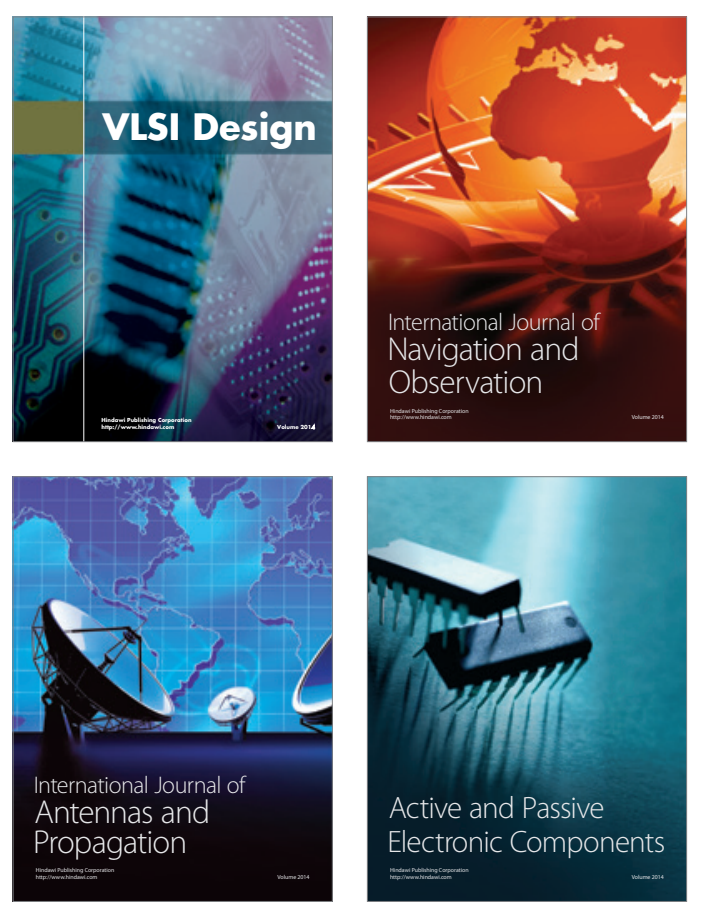
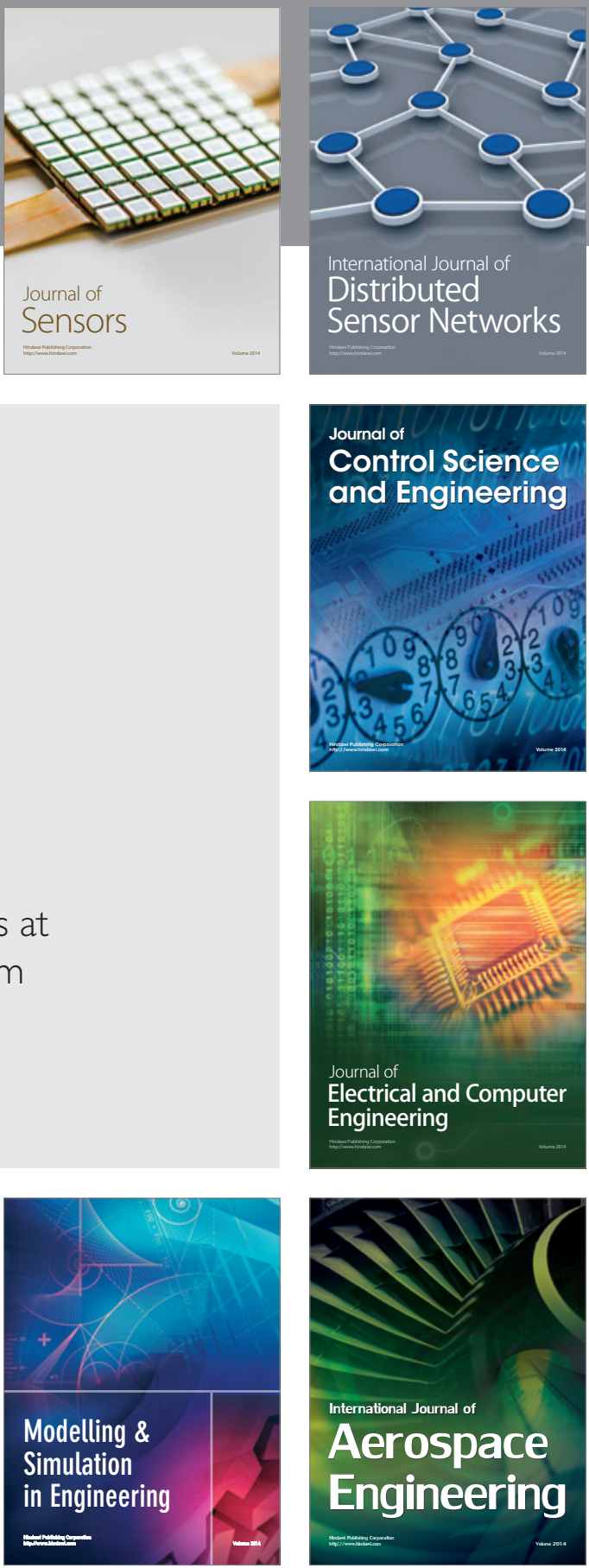

Journal of

Control Science

and Engineering
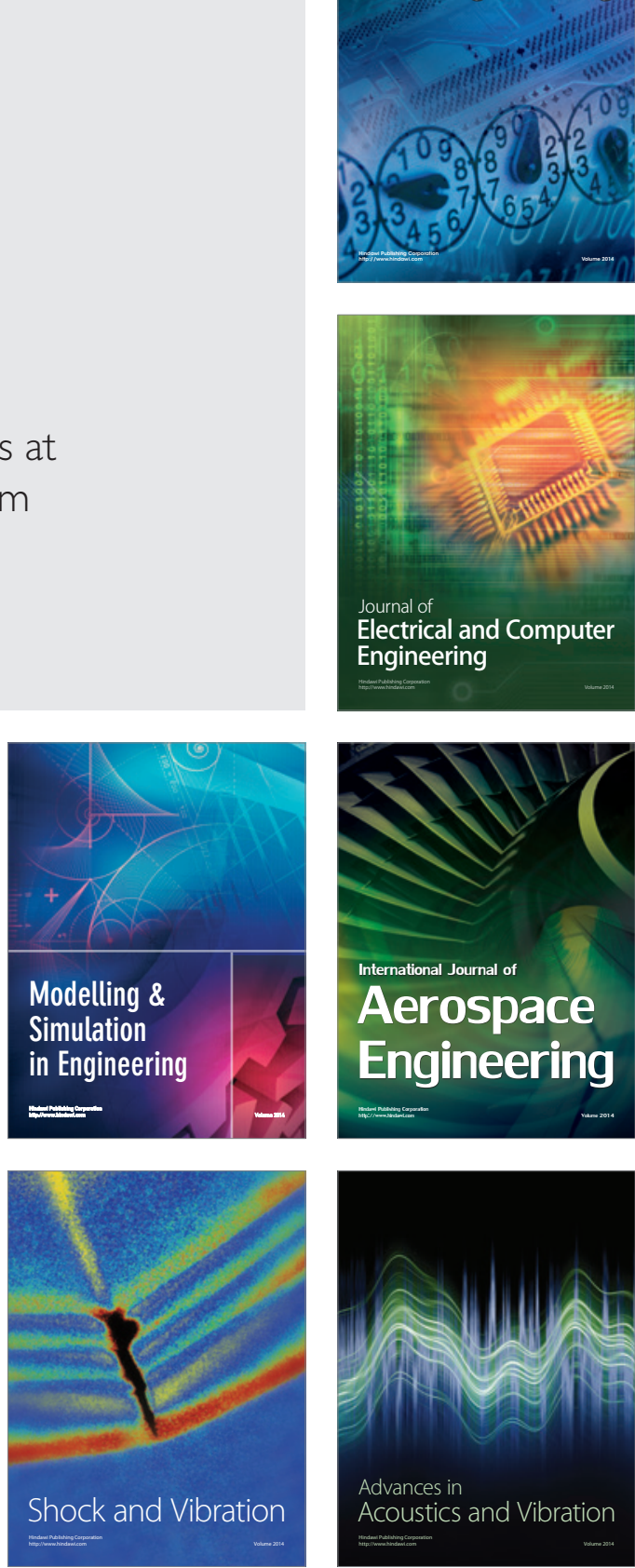